\title{
A Web-enhanced Course in Foundation Program at Bahrain Teachers College: A Case Study
}

\author{
Malik, N.K., Al Shaer, F., and Arora, B.
}

Corresponding Author:

Malik, N.K.

Received: 10 July 2019

Accepted: 4 September 2019

Published: 12 September 2019

Publishing services provided by Knowledge E

(c) Malik, N.K. et al. This article is distributed under the terms of the Creative Commons

Attribution License, which permits unrestricted use and redistribution provided that the original author and source are credited.

Selection and Peer-review under the responsibility of the Foundation Programs - Shaping the Future of ELT Conference Committee.

\section{Abstract}

The purpose of a web-enhanced course in Study Skills at Bahrain Teachers College (BTC) was to reduce the time consumed in teaching, learning and assessing while dealing with large classes. Thus, the current study is a case in exploring the effectiveness of using different aspects of technology in teaching. Conceptualized by Stella Cottrell, the APT-S framework of study skills focuses on Academic skills, People's, Task and Self-management skills, and that formed the basis of the Study Skills course. The technology engaged in this investigation consisted of BTC's Learning Management System-Moodle, computer labs, and students' personal mobile devices. Through the e-content on Moodle, the course incorporated technology with online activities, online quizzes, QR codes, active excel sheets and optical answer sheets. Emails and WhatsApp groups formed the medium of communication with students. A variety of online teaching strategies included video lectures, flipped class model, live Instagram session, online discussion forums, and several interactive in-class fun activities. Periodic assessments of small portions of the content and reflective learning tasks that promoted critical thinking were the other highlights of the course. The sample for the current case study comprised of 366 Foundation program students at BTC. The qualitative data was collected in the form of the students' reflections and feedback on the open-ended questions as well as the insights from the 3 course instructors. Unstructured interviews were also conducted with 14 students. Overall, the case study concluded that the blended/online learning for Study Skills course made the teaching and learning process more efficient and ensured a larger number of online participation from students than in a normal classroom. The effectiveness in the use of technology, through a flip classroom, a live Instagram session and video lectures, wasclearly evident. Due to the challenges posed by the logistics of conducting frequent assessments and recording video lectures without professional support, it is recommended that BTC should be equipped with sufficient computer labs and professional recording equipment.

Keywords: web-enhanced, study skills, online teaching strategies, foundation program, online learning 


\section{Introduction}

According to the third pillar of the University of Bahrain's (UOB), Academic Plan for 2016-2021, 'linking research publications and interest with content of the courses will improve the students' ability to provide innovative solutions to contemporary issues" (p.11).Hence, the current study is a case in developing Study Skills as a web-enhanced course in the pre-university foundation program at Bahrain Teachers College (BTC). Based on Stella Cottrell's APT-S framework, the course focuses on developing four skills; academic skills, people skills, task management, and self-management skills to prepare fresh school graduates who succeed as college students.Blending the content with the web-enhanced pedagogy, also intends to meet the UOB's Academic Plan values of 'innovation', 'student centered', 'technology driven', 'proactive', and 'transparent. Online education has become compulsory in most higher education institutions for delivering totally online or blended learning programs (Hernández-Gantes, 2012), especially given the increase in online learners and faculty teaching online over the past decade (Yagodzinski, 2012).Fresen refers to the terms online learning, e-learning, web-supported learning and technology enhanced learning synonymously as TEL (Technology Enhanced Learning). She defined blended learning as, "using the face-to-face and distance environments for what each does best, blending them together in a complementary way to design and deliver effective and satisfactory learning experiences for students." (Fresen, 2018, p.228).Studies examining students' perspectives in higher education showed that students have high expectations from the way that they learn and being taught, implemented technologies, learning environment and how their needs are met in the best way (Conole\&Creanor, 2007). Thus, universities are expected to offer technology rich course components either in blended or fully online modes through using web tools (Asterhan\& Schwarz, 2010) to keep pace with the needs and characters of the new generation of students.

For quality web-technology integration, Trentin and Alvino (2011) stressed on two key dimensions which are pedagogical and professional dimensions related to each other with technology. The pedagogical dimension concerns about the pedagogical potentialities added to the teaching and learning processes when utilizing web technologies. Similarly, the professional dimension concerns about the professionalism of faculty when using e-Learning strategies.Zhao, Pugh, Sheldon \& Byers (2002) outlined three factors influencing the success of any technology utilization in teaching and learning: (1) Innovator factors which refer to the faculty's technological competencies, pedagogical compatibility and social alertness, (2) Innovation factors which refer to the 
nature of the technology itself relaying on the existing practice, culture, technological resources and human resources, (3) Context factors which refer to the availability of human infrastructure (technical and administrative staff), technological infrastructure (resources, access and services).A study conducted by Owston, York and Malhotra (2019), examined and compared student perceptions on design, interaction, learning and satisfaction. Five fine arts courses offered in the first year of a public university with large enrolment were redesigned with 4 different combinations: Class lectures/ tutorials, web-enhanced; Class lectures/ online tutorials; Online lectures/ in-class tutorials; and Class lectures/ hybrid tutorials which alternated weekly between 2 hour lectures and 1 hour face to face tutorial. The results showed that,on design and overall satisfaction, online lectures and in-class tutorial were rated significantly higher than the three other models. Vo, Zhu and Diep (2017) analyzed the impact of blended learning on the academic achievement of higher education students. The study covers 40 articles out of all the 14,891 articles published from the year 2001 to 2015 that meet the inclusion criteria in the selection process. The comprehensivemeta-analysis software was used for data analysis to measure student performance by final course grades and subjects of study as moderating variables. The study confirmed significantly higher impact of blended learning on the performance of students.

\section{Aim}

To provide a web enhanced course in Study Skills to the foundation program students at BTC

\section{Research Questions}

1. How was technology engaged in making the Study Skills a web-enhanced course?

2. How did the technology help in managing classrooms with large student numbers?

3. How did technology make teaching, learning and assessment more effective?

\section{Rationale}

BTC introduced Moodle to its students in 2009. Since the faculty at BTC has been regularly trained in its use, in the current study, the researchers explore the potential of technology in teaching through this preferred platform over Blackboard available 
to all University of Bahrain (UOB) faculty and students.This feature enabled faculty to connect with their students online synchronously (through live chat option) as well as asynchronously (through options for forums, comments and messages). Since there is a widespread and easy access to technology for every youth these days, to deal with the rising number of students in the pre university foundation program at BTC the current study engaged high use oftechnologyto keepmaximum students on task. The use of selected aspects of technology such as online forums, online activities, and social media to name some was considered best as students have a ready access to them along with being well versed in their use.The study was also intended to investigate if the use of technology made a difference in teaching students to manage their time and tasks better and develop good people skills.

\section{Significance}

The study will be significant for colleges with rising student numbers in classrooms by proving cost effective solutions. This means that any technology based learning management platform (For example, Moodle or Blackboard) that a collegeis part of, can be engaged optimally for teaching, learning and assessing courses at no added cost. The study will also be significant for the instructors as it engages technology that does not need special training and skills. The instructors can engage any freely available software applications in creating course materials (For example, Screencast or Camtasia for video lessons). The study will also benefit students as they are very proficient in the use of technology. Hence, the use of technology in teaching will engage their interest and attention more compared to the traditional teaching method.

\section{Delimitations}

The study is delimited to the foundation program students at BTC. For the study, technology was integrated only in the Study Skills course offered in the first semester of the foundation program in 2018-2019.The study is also restricted to the technology available for use of students and instructors at BTC, along with the use of free online applications (Screencast) and access to specific social media (Instagram). 


\section{Methodology}

The current case study is a qualitative research that adopts the Technological Pedagogical Content Knowledge (TPACK) framework by Mishra and Kohler (2006) towebenhancethe course in Study Skills at the foundation level program in BTC.This framework engages a combination of content, pedagogical and technological knowledge needed to successfully embed web-tools and e-learning strategies in teaching and learningto ultimately present the content in an interactive and engaging online environment. Moodle-LMS, considered as one of the innovations emerging directly from the e-Learning industry and sustained as a part of e-Learning ecosystem until today (Davis, Carmean and Wagner, 2009), was the selected e-platform of this study. This served as an essential tool for designing curriculum and managing students learning and motivation because it offers many features and functions that enable online content delivery, facilitate online communication and online interaction among faculty and students, manage online tests and online assessments, track learners' performance, generate reports and promote collaborative online learning (Cavus, 2009). Hence, to develop academic skills, video lectures were produced using screen capturing tools to demonstrate the specific skills such as APA citing and referencing with real practicing examples. These e-lectures were streamed on Moodlefor self-paced learning. Online games and activities were also embedded through Moodle for practice of these skills and get instant feedback. To develop people skills and opportunities for reflection through social communication (Dewey, 1959), online forums were created on Moodle on a weekly basis. For task management skills, Moodle facilitated the online selfassessment quizzes for practice and also the online summative assessment. All exam related instructions and protocols were uploaded on Moodle with illustrations. The students also learned to submit online assignments successfully. For managing self, an active excel sheet was created for a daily log of activities to calculate the estimated time for each activity and categorize the activities automatically. Students were asked to reflect upon the course and its delivery at the end of the course.

According to Moore (1989), there are three typologies of interactions framework in distance education which can be used for web-enhanced courses: a) Learner-Content Interaction: where learners access online resources, b) Learner-Instructor Interaction: where learners interact with the instructor in a fully online environment and c) LearnerLearner Interaction: where learners build a network enabled educational environment. Thus, the course incorporated thesedifferent kinds of interactions. As for LearnerContent Interaction, the course was enhanced with weekly online plans uploaded to 
Moodle containing access to e-content, e-resources and video lectures, online activities and self-assessment quizzes where students can apply and practice the learnt skills and assess their understanding. QR codes were also used for accessing crib sheets anywhere and anytime in addition to creating an active excel sheets for keeping daily log of activities. On the level of Learner-Learner Interaction, the course incorporated active discussion topics on Moodle where students had to share their own views and insights with others. In addition, Instagram live session was used to conduct live video meeting with a graduate student. For the Learner-Instructor Interaction, forums, emails and WhatsApp groups formed the medium of communication.

\section{Sample Size}

The overall sample for the study consisted of 366 foundation program students in their semester one at BTC in the UOB. Of the total sample, reflections from 14 students were selected randomly. A reachable and purposive sampling approach was used to conductthe unstructured interviews with 14 students ( 7 females and 7 males) who were judged best in providing rich information on their learning outcome in the course.

\section{Data Collection Tools}

The data was collected from all students in the form of reflections on the course content and delivery. Semi structured interview schedule with 5 questions, constructed and reviewed by the three course instructors, were also used to collect data. Feedback on the course was also contributed by the course instructors. Hence, the data consists of direct quotations from students and instructors about their experiences.

\section{Data Analysis}

To enhance the validity of the current research, the data was analyzed using inductive analysis based on the frequent vocabulary and common answers identified in the studentreflections on the course and its delivery, instructor feedback, and student interview transcripts. Predetermined categories and themes, based on the interview questions, were also formed to interpret data.To increase the reliability of the current research, categories, themes, and codes are supported by examples of student responses in the tables. In a qualitative research, since hypotheses are not specified precisely, they cannot be tested statistically. Instead, the analysis of data in a qualitative research 
involves triangulation to converge and synthesize the information obtained from various sources (such as reflections, interviews, and feedback in the current study) to build a comprehensive understanding of the phenomena (Patton, 1999). Since the data describes only a single study group, generalizations cannot be made. The conclusions of the current study are therefore limited to the sample of the study. However, the analysis of categories and themes does help other researchers to comprehend results of similar cases in otherstudies (Büyüköztürk et al., 2008). For analysis, code $\mathrm{S}$ denotes student reflections, code SS denotes student interviews, and code I denotes instructor.

\section{Results}

The Study Skills Category I (based on student reflections)

TABLE 1: Students' Reflections (Theme: Biggest strength).

\begin{tabular}{l|l}
\hline Theme & Student code and examples of their responses \\
\hline Biggest strength & Subtheme: Self-management \\
& S1: "I can manage myself when I feel nervous" \\
S10: "If I have a problem with subject, I research to know the answer" & S9: "I can manage my time" \\
& S8: "Before every week, I put a plan for everything" \\
S14: "I make weekly plan and follow this plan" & S11: "I know which time I can study, play or do other things" \\
& Subtheme: People skills \\
& S7: "I love to study with my friends" \\
& S6: "I feel more responsible" \\
& S2: I can learn more things and understand more"
\end{tabular}

TABLE 2: Students' Reflections (Theme: Biggest challenge).

\begin{tabular}{l|l}
\hline Theme & Student code and examples of their responses \\
\hline Biggest challenge & Subtheme: Self-management \\
& S2: "I'm not good in organizing my time" \\
S15: "Dependence on myself is most difficult" & Subtheme: People skills \\
& S11: "I'm too shy" \\
S8: "I face many difficulties in communication with my partner" & S1: "I prefer to do my work alone" \\
S3: "I am trying hard to be more flexible" & Subtheme: Academic skills \\
& S12: "I don't have an idea how to study" \\
& S5: "I can't answer all questions perfectly" \\
& Subtheme: Task-management \\
& S6: "I leave the tasks for the next day" \\
& S13: "I don't know how to do my assignment alone"
\end{tabular}


TABLE 3: Students' Reflections (Theme: Most improved skill).

\begin{tabular}{l|l}
\hline Theme & Student code and examples of their responses \\
\hline Most improved skill & Subtheme: Self-management \\
& S1: "I know how to write a weekly plan" \\
& S10: "I learned how to ask my instructor" \\
S5: "I manage all my tasks well" \\
& S6: "I try to finish all my work and studies on my own" \\
S2: "I always motivate myself" \\
S15: "I learned how to manage my life" \\
S1: "I developed this skill and I am very well with it" \\
& Subtheme: People skills \\
& S8: "I try to engage myself in many activities" \\
& S12: "I improved my talk and communication with people" \\
& S13: "We have to work as a group" \\
& S9: "I have more confidence to communicate with others" \\
& S14: "I go to Early Bird to improve my English" \\
& Subtheme: Academic skills \\
& S11: "I can reference the sources" \\
& S3: "I can take notes in my own words" \\
& S4 "I can make good decisions for studying"
\end{tabular}

The Study Skills Category II (based on student interviews)

TABLE 4: Student Interviews (Theme: Most preferred technology).

\begin{tabular}{l|l}
\hline Theme & Student code and examples of their responses \\
\hline Most preferred & SS1, SS2: "weekly plan" \\
technology & SS14, SS11, SS7, SS4: "online activities" \\
& SS13, SS12, SS8, SS9, SS5: "Moodle upload of course", "forums" \\
& SS6, SS3, SS10: "Instagram live"
\end{tabular}

TABLE 5: Student Interviews (Theme: Most difficult technology).

\begin{tabular}{l|l}
\hline Theme & Student code and examples of their responses \\
\hline Most difficult & SS10: "video lectures" \\
technology & SS1: "daily log" \\
& SS12, SS13, SS3: "Instagram live" \\
& SS9, SS5, SS4, SS7, SS11: "Moodle upload of course" \\
& SS6, SS8, SS14: "forums"
\end{tabular}

TABLE 6: Student Interviews (Theme: Most observed improvement).

\begin{tabular}{|c|c|}
\hline Theme & Student code and examples of their responses \\
\hline $\begin{array}{l}\text { Most observed } \\
\text { improvement }\end{array}$ & $\begin{array}{l}\text { SS9, SS3, SS12, SS8, SS10: "Moodle forums improved our writing" "in } \\
\text { English courses I got good grades" "effected in Biology and Chemistry" } \\
\text { "study other subjects and understand them" "I learned how to upload my } \\
\text { assignment" } \\
\text { SS6: "I applied note taking strategy" } \\
\text { SS5: "video lectures helped me in other courses" }\end{array}$ \\
\hline
\end{tabular}

The Study Skills Category III (based on instructor feedback) 
TABLE 7: Instructor Feedback (Theme: Benefits of blending technology).

\begin{tabular}{l|l}
\hline Theme & Instructor code and examples of their responses \\
\hline $\begin{array}{l}\text { Benefits of } \\
\text { technology }\end{array}$ & $\begin{array}{l}\text { I1: "improved and regular communication with students" " better student } \\
\text { engagement in class due to better class-time utilization" "enjoyed a new } \\
\text { perspective on the course" "an opportunity to experience } 21 \text { st century teaching } \\
\text { skills" } \\
\text { I2: "saved large amount of time, paper, and printing ink" "engaged learners in } \\
\text { and outside class time" "made learners better prepared for class" "forums } \\
\text { provided opportunities to practice writing" "video lessons helped review the } \\
\text { lesson till the concept was clear" "WhatsApp served as a backup to send } \\
\text { materials when Moodle would crash" "online activities helped practice of } \\
\text { learned concepts" "interactive daily log helped in easy completion of task" } \\
\text { I3: "prepare future teachers to make a noticeable impact in the quality of } \\
\text { education in Bahrain's schools" "teaching and learning were extended beyond } \\
\text { time and place" "students were able to attempt these (online) activities multi- } \\
\text { times and they were provided with instant feedback" "they (students) found } \\
\text { them (e-lectures) very useful and essential for their studying, revising and } \\
\text { completing their assignments" "Arabized summary was added to a note section } \\
\text { by the end of each topic in the e-lecture which helped students" }\end{array}$
\end{tabular}

TABLE 8: Instructor Feedback (Theme: Challenges of blending technology).

\begin{tabular}{l|l}
\hline Theme & Instructor code and examples of their responses \\
\hline $\begin{array}{l}\text { Challenges of } \\
\text { Blending }\end{array}$ & I1: "significant increase in class preparation time" "inadequate technical \\
technology & resources and infrastructure" "developing a fair and reliable system of online \\
assessment" & I2: "deriving a better strategy for online assessments of large student group" \\
& $\begin{array}{l}\text { "time consuming online grading of assignments" "allowing students to access } \\
\text { content on their mobiles during teaching can be hard to monitor their honesty in } \\
\text { staying on task" "video lectures need more professional production device" } \\
\text { I3: "change students learning habits to be more self-learners and self-directed" } \\
\text { "lack of IT infrastructure" "an equipped video and audio studio" }\end{array}$
\end{tabular}

\section{Discussion}

To answer the first research question in this study, how was technology engaged in making the Study Skills a web-enhanced course, the course Study Skills systematically integrated several technology aspects relying on their availability and ease of use for both students and instructors. The course materials were prepared and uploaded periodically ahead of time on Moodle so students could have enough time to print materials and read, if required, to prepare for class. The uploaded materials comprised of content slides as well as handouts for class work and some online practice activities. Games and online puzzles were also added for fun and consolidation of learning. Weekly Moodle forums were also created to engage students in discussions and give them practice in writing without fear of grading. Some topics were selected to video record the lesson for self-study todevelop learner autonomy.A session on Instagram live was scheduled with the award winning ex-student of the college to take live questions from 
the students on benefits of study skills in life after college. The analysis of data serves as a guide to student preferences of the technology used.

Most students, found it very useful to have all materials available online. Students found the forums a good way of practicing writing and sharing their views. While course instructors benefited from having more structured class time with activities well planned ahead of time, this was a challenge to accomplish due to producing a vast variety of materials for student interests.To answer the second research question, how did the technology help in managing classrooms with large student numbers, the course Study Skills made use of Moodle for conducting large group assessments online. While thegrading of the online assessment was instant at the time of completion of the quiz, the logistics of conducting the quiz for large groups defeated the objective of planning the task. The online assessment of a large group is a challenge and a limitation due to available desktop units and their sudden technical inefficiency. However, the interactive online games and puzzles were very effective in engaging large number of students at the same timeand keeping them on task. The video lessons were also produced for students to review the concept a number of times till they get it. The online forums also accommodated a large number of students to join in the discussion asynchronously. Since language was not graded, students with weak language skills also responded with posting comments on the forums. This enabled students of all levels to participate. An activity log was maintained for grading participation. To answer the third research question, how did technology make teaching, learning and assessment more effective, the course Study Skills prepared two sets of power points on all topics. While one set was uploaded on Moodle for students to read before the class and prepare any questions on it for the class, much like a flipped classroom experience, the second set was for the instructors to use in class. Added to this were worksheets with online games and activities for practice. Furthermore, forums on Moodle gave students a chance to discuss the concepts being learned. This also gave them opportunity to fill their knowledge gaps and improve their understanding by reading posts by other students on the forum. Integration of technology in the Study Skills course did not benefit the summative assessment. However, it provided a range of formative assessment options. The use of online games, activities, forums offered engaging instructional opportunities for all levels of learners. They were a source of quick assessment of student learning. In this qualitative research, the views of students indicate an overall positive effect on their study skills as a result of using technology in reaching out to them. It is therefore recommended that educators should integrate technology in teaching and learning as 
our students today may take time to master traditional reading and writing skills, but they are far well versed in reading and writing digital content which is native to them.

\section{References}

[1] Asterhan, C. S., \& Schwarz, B. B. (2010). Online moderation of synchronous e- argumentation.International Journal of Computer-Supported Collaborative Learning, 5(3), 259-282.

[2] Büyüköztürk, Ş., Çakmak, Kııç, E., Akgün, Ö. E., Karadeniz, Ș., \&Demirel, F. (2008). Bilimselaraştırmayöntemleri. Ankara: PegemYayınevi.

[3] Cavus, N. (2009). Collaborative learning \& learning management systems: Collaborative learning\& LMS. Ko囚ln: LAP Lambert Academic Publishing.

[4] Conole, G., \&Creanor, L. (2007). In their own words: Exploring the learner's perspective on e-learning. London, England: JISC. Retrieved October 30, 2007 from http: //www.jisc.ac.uk/media/documents/programmes/elearningpedagogy/iowfinal.pdf

[5] Coyner, S., \& McCann, P. (2004). Advantages and challenges of teaching in an electronic environment: The ACCOMMODATE model. International Journal of Instructional Media 31(3), 223-228.

[6] Davis, B., Carmean, C. \& Wagner, E. (2009). The evolution of the LMS: From management to learning: Deep analysis of trends shaping the future of e-learning. The eLearning Guild Research. Retrieved June 18, 2010, Retrieved from: http: //www.elearningguild.com/showfile.cfm?id=3703

[7] Dewey, J. (1959). Dewey on education (Vol. 3). Bureau of Publications, Teachers College, Columbia University.

[8] Fresen, J. W. (2018). Embracing distance education in a blended learning model: Challenges and prospects. Distance Education, 39 (2), 224-240.

[9] Herbert, C., Velan, G.M., Pryor, W. M., \& Kumar, R. K. (2017). A model for the use of blended learning in large group teaching sessions. BMC Medical Education, 197 (17). DOI 10.1186/s12909-017-1057-2

[10] Hernández-Gantes, V. M. (2010). Emerging framework for planning and implementation of online programs. International Journal of Adult Vocational Education and Technology (IJAVET), 1(4), .1-16

[11] Hung, M. \& Chou, C. (2015). Students' perceptions of instructors' roles in blended and online learning environments: A comparative study. Computers and Education, 81, 315-325. 
[12] Mishra, P., \& Koehler, M. J. (2006). Technological pedagogical content knowledge: A Framework for teacher knowledge. Teachers college record, 108(6), .1017

[13] Moore, M. G. (1989). Three types of interaction. The American Journal of Distance Education, 3(2), 1-6.

[14] Owston, R., York, D., \& Malhotra, T. (2019). Blended learning in large enrolment courses: Student perceptions across four different instructional models. Australasian Journal of Educational Technology, 35 (5), 29-44.

[15] Patton, M. Q. (1990). Qualitative evaluation and research methods (2nd ed.). London: Sage Pub.

[16] Trentin, G., \& Alvino, S. (2011) Faculty training for web enhanced learning. In M. Trentin,

G., \& Alvino, S. (2011). Faculty training as a key factor for Web Enhanced Learning sustainability. Faculty Training for Web-Enhanced Learning, .1-19

[17] University of Bahrain. (2016). Academic Plan 2016-2021. Bahrain: University of Bahrain

[18] Yagodzinski, E. D. (2012). Formative research on an instructional design theory for online learning communities: A higher education faculty development case. ProQuest LLC. 789

East Eisenhower Parkway, P.O. Box 1346, Ann Arbor, Ml 48106. Tel: 800-521-0600; Web site: http://www.proquest.com/en-US/products/dissertations/individuals.shtml

[19] Vo, H. M., Zhu, C., \& Diep, N.A. (2017). The effect of blended learning on student performance at course-level in higher education: A meta-analysis. Studies in Educational Evaluation, 53,17-28.

[20] Zhao, Y., Pugh, K., Sheldon, S., \& Byers, J. L. (April 01, 2002). Conditions for classroom technology innovations. Teachers College Record, 104, 3, 482-515. 